\title{
What Works in Fighting Diarrheal Diseases in Developing Countries? A Critical Review
}

Alix Peterson Zwane • Michael Kremer

The Millennium Development Goals call for reducing by half the proportion of people without sustainable access to safe drinking water. This goal was adopted in large part because clean water was seen as critical to fighting diarrheal disease, which kills 2 million children annually. There is compelling evidence that provision of piped water and sanitation can substantially reduce child mortality. However, in dispersed rural settlements, providing complete piped water and sanitation infrastructure to households is expensive. Many poor countries have therefore focused instead on providing communitylevel water infrastructure, such as wells. Various traditional child health interventions have been shown to be effective in fighting diarrhea. Among environmental interventions, handwashing and point-of-use water treatment both reduce diarrhea, although more needs to be learned about ways to encourage households to take up these behavior changes. In contrast, there is little evidence that providing community-level rural water infrastructure substantially reduces diarrheal disease or that this infrastructure can be effectively maintained. Investments in communal water infrastructure short of piped water may serve other needs, and may reduce diarrhea in particular circumstances, but the case for prioritizing communal infrastructure provision needs to be made rather than assumed. JEL codes: Q56, Q52, O22

The sole quantitative environmental target in the Millennium Development Goals is the call to "reduce by half the proportion of people without sustainable access to safe drinking water." Providing water has a number of benefits, but a key rationale for this goal is the impact of poor quality water on human health, particularly on diarrheal disease, which kills 2 million children in poor countries each year (WHO 2002; Kosek, Bern, and Guerant 2003).

(C) The Author 2007. Published by Oxford University Press on behalf of the International Bank for Reconstruction and Development / THE WORLD BANK. All rights reserved. For permissions, please e-mail: journals.permissions@oxfordjournals.org doi:10.1093/wbro/lkm002 Advance Access publication May 4, 2007 
Providing piped water and sanitation infrastructure can drastically reduce child mortality. In the United States, these interventions were jointly responsible for most of the rapid decline in the child mortality rate in the early 20th century (Cutler and Miller 2005), and more recently for substantial health improvements on Native American reservations (Watson 2006). For this class of interventions, a key outstanding question is what institutional arrangements can best support investment in infrastructure and its maintenance. Galiani, Gertler, and Schargrodsky (2005) find major health gains from privatization of water service in Argentina in the 1990s.

However, it is expensive to provide piped water and sanitation to dispersed rural populations, and many countries find this beyond their means. In much of Africa, rural residents typically live on their farms rather than being concentrated in villages. In such circumstances, policy often focuses on providing improved drinking water sources outside the home, such as communal taps, wells, and protected springs. About 30 percent of people living in rural areas of developing countries (or about 926 Million people) lack a safe and accessible water supply as defined by the World Health Organization (a communal standpipe or borehole well within a reasonable distance) (WHO 2000). Nearly all of the $\$ 5.5$ billion, the World Bank invested in rural water and sanitation programs during 1978-2003 focused on improving water supply sources and quality through interventions such as well digging (Iyer and others 2006).

This article critically reviews the research on what works in preventing and treating diarrheal diseases in developing countries. It examines evidence on the medical effectiveness of a series of alternative means of fighting diarrhea and on ways of encouraging the individual or collective behavior necessary for uptake. ${ }^{1}$

A series of randomized trials have established that several child health interventions-including exclusive breastfeeding, immunization, oral rehydration therapy, and micronutrient supplementation-are effective in preventing or treating diarrhea. Several interventions that rely on individual behavior change have also been shown to be effective. Researchers have convincingly demonstrated that increased handwashing can significantly reduce diarrhea incidence (Khan 1982; Han and Hlaing 1989; Luby, Agboatwall, Razz and others 2004), and randomized impact evaluations of point-of-use water treatment systems (disinfection of water in the home, for example) suggest that these technologies can reduce diarrhea incidence some 20-30 percent (Quick, Venczal, and others 1999; Reller and others 2003). Identifying successful strategies for promoting adoption is an important next step.

While there is a large body of evidence for the effectiveness of piped water in the reduction of diarrhea incidence, there is much less evidence for the effectiveness of the provision of communal rural water infrastructure and latrines. Although several older prospective studies appear to identify large impacts of this 
class of interventions, these works have important methodological shortcomings. They relied on analyses of data from a handful of sites, were conducted in ways that make it difficult to disentangle the impact of provision of improved communal water sources from latrine construction, and were not based on random assignment of communities. More recent work based on randomized trials with large samples does not find substantial health impacts from improved communal water sources (Kremer and others 2006). Moreover, while rural water facilities can be long-lived if properly serviced, they often fall into disrepair quickly due to poor maintenance, and though many different approaches to maintenance have been advocated, there is little evidence on their relative effectiveness.

Because of the lack of evidence on effectiveness and the maintenance challenge, the case has not been made for prioritizing communal rural water infrastructure for fighting diarrheal disease. Investing in piped water and sanitation in areas where that is feasible and expanding the provision of standard child health interventions have both been shown to work. Finding ways to effectively promote handwashing and point-of-use water treatment also seems a priority. In some circumstances, there may be a strong case for investing in rural water infrastructure for other reasons, and in some environments such infrastructure may have important health benefits. But the case for prioritizing communal water infrastructure will need to be made rather than assumed.

This article first provides a brief background on water-related diseases and their transmission and discusses traditional child health interventions that prevent and treat diarrhea. Next, it reviews the evidence on individual behavior change interventions that can prevent diarrhea, including handwashing and point-of-use water treatment systems, and discusses the outstanding question of how to induce people to adopt these methods. It then reviews the evidence on the effectiveness of source water quality improvements and sanitation investments, and discusses the challenge of rural infrastructure maintenance. Finally, it sketches an agenda for further work.

\section{Child Health Interventions}

Water destined for human contact that is exposed to the environment is a potential source of diarrheal disease. In developing countries, in particular, surface water is often contaminated with pathogens (including bacteria, viruses, and parasites) due to contact with human and livestock waste. Drinking, handling, cooking, and bathing in such water exposes people, especially young children, to a wide range of health risks, including diarrheal diseases. Moreover, the lack of adequate water of any kind reduces the opportunity to wash people, food, dishes, and clothes and thus contributes to the spread of disease. 
Table 1. Transmission Routes of Water-Related Diseases

\begin{tabular}{|c|c|c|}
\hline Classification & Transmission route & Examples of diseases transmitted \\
\hline Waterborne & Through ingestion of pathogens in drinking water & $\begin{array}{l}\text { Diarrheal diseases } \\
\text { Enteric fevers, such as typhoid } \\
\text { Hepatitis A }\end{array}$ \\
\hline Water-washed & $\begin{array}{l}\text { Through incidental ingestion of pathogens in the } \\
\text { course of other activities; results from having } \\
\text { insufficient water for bathing and hygiene }\end{array}$ & $\begin{array}{l}\text { Diarrheal diseases } \\
\text { Trachoma } \\
\text { Scabies }\end{array}$ \\
\hline Water-based & $\begin{array}{l}\text { Through an aquatic invertebrate host; results } \\
\text { from repeated physical contact with } \\
\text { contaminated water }\end{array}$ & $\begin{array}{l}\text { Guinea worm } \\
\text { Schistosomiasis }\end{array}$ \\
\hline $\begin{array}{l}\text { Water-related insect } \\
\text { vector }\end{array}$ & $\begin{array}{l}\text { Through an insect vector that breeds in or } \\
\text { near water }\end{array}$ & $\begin{array}{c}\text { Malaria (parasite) and } \\
\text { yellow fever (virus) }\end{array}$ \\
\hline
\end{tabular}

One standard method of classifying the disease burden associated with water summarizes the potential health costs of relying on unsafe water according to pathogen transmission path (table 1). In this taxonomy, diarrheal diseases are spread through fecal-oral transmission and fall into both, the waterborne and water-washed categories (White, Bradley, and White 1972; Cairncross 1996; IIED 2000). The health cost of diseases transmitted in this way is tremendous, and falls disproportionately on young children. Diarrheal illnesses accounted for at least 8 percent of total lost disability-adjusted life years in developing countries in 1990 (Smith, Corvalan, and Kjellstrom 1999) and for some 20 percent of deaths among children under age five (Kosek and others 2003). Acute diarrhea can result in severe dehydration, and persistent diarrhea may predispose children to malnutrition (Briend 1990; Schorling and others 1990; Lancet 1991; Guerrant, Lima, and Davidson 1992), making them more susceptible to other infectious diseases. Prospective (though nonrandomized) community-based fieldwork in Sub-Saharan Africa summarized by the Child Health Research Project (CHR 1998) concludes that diarrhea leads to impaired weight gain, particularly in infants less than 1year old and those not exclusively breastfed. Malnutrition is in turn associated with increased risk of death from childhood illnesses (Pelltier and others 1995). ${ }^{2}$

Several child health interventions-including breastfeeding, immunization against diarrheal diseases, oral rehydration therapy, and micronutrient supplementation - have been shown to be both effective and cost-effective in treating and preventing diarrhea in a series of randomized trials (for a review see Hill, Kirkwood, and Edmond 2004).

Exclusive breastfeeding is widely accepted as a means of preventing diarrhea in infants up to 6 months of age, and continued breastfeeding also has protective 
effects for older children (Perera and others 1999; Raisler, Alexander, and O'Compo 1999; WHO Collaborative Study Team 2000). Weaning foods prepared in unhygienic conditions are frequently heavily contaminated with pathogens, and are thus a cause of diarrhea and associated malnutrition (Motarjemi and others 1993; Hendricks and Badruddin 1994; Monte and others 1997; Lanata 2003). Interventions to improve nutrition during weaning compliment interventions that encourage early exclusive breastfeeding and extended breastfeeding.

Rotavirus is a leading cause of severe diarrheal disease and dehydration in infants. It most frequently attacks children 6-24 months and causes 20 percent of all diarrheal deaths among children under age five (Motarjemi and others 1993). In developing countries, rotavirus gastroenteritis is responsible for approximately half a million deaths per year among children under age five (Parashar, Bresee, and Glass 2003). Two new vaccines have shown efficacy against rotavirus gastroenteritis (Ruiz-Palacios and others 2006; Vesikari and others 2006) and are now on the market. The inclusion of these vaccines in national vaccination programs is a promising intervention against diarrheal disease and mortality.

Oral rehydration therapy appears to have been responsible for significant reductions in diarrheal mortality since 1980 (Miller and Hirschhorn 1995; Victora, Olino and others 1996; Victoria, Bryce and others 2000). Micronutrient supplementation, including therapeutic and preventative supplementation with zinc and therapeutic supplementation with vitamin A, has also been found to have positive impacts on diarrheal disease and death (Beaton and others 1993; Black 1998; Ramakrishnan and Martorell 1998; Zinc Investigators' Collaborative Group 1999, 2000; Grotto and others 2003).

As coverage is still incomplete, finding ways to increase access to traditional child health programs in an affordable way remains critical. For example, continuous zinc supplementation can be costly where high levels of home food production make fortification infeasible and households must be induced to adopt micronutrient "sprinkles" sachets (USAID 2004; Zlotkin and others 2005). Similarly, identifying effective mechanisms for encouraging breastfeeding and consistent use of oral rehydration therapy remains a challenge (Sikorski and others 2003).

\section{Individual-Level Behavior Change}

Individual choices and investments, such as handwashing and point-of-use water treatment (including improved storage), can break the chain of transmission of fecal-oral diseases. This section reviews the evidence on the health impact of these hygiene behavior modifications, and discusses the need for further work investigating how to increase uptake of these behaviors. 


\section{Handwashing}

Hands are a common vector for the transmission of fecal-oral diseases (Curtis, Cairncross, and Yonli 2000). Handwashing with soap after defecation, after cleaning children, and before and after food handling can interrupt this diarrheal disease transmission path.

The effectiveness of handwashing as a means of reducing diarrhea has been convincingly established in several settings. Luby, Agboatwall, Razz, and others (2004) report the results of a recent cluster-randomized trial in a large sample of households in Karachi, Pakistan, of a handwashing promotion campaign aimed at mothers. Infants and malnourished children under age five living in treatment households had 39 percent fewer days of diarrhea compared with the control group after 1 year of intervention and observation. Gains roughly doubled after a second year of promotion as relatively poor households increased their compliance (Luby, Agboatwall, Painter, and others 2004).

A recent survey of the literature evaluating the effect of handwashing with soap on diarrhea risk in developing countries (Curtis and Cairncross 2003) identified two other randomized controlled trials with more than two communities in their samples (Khan 1982; Han and Hlaing 1989). Each study had a relatively large sample size randomly divided into treatment and control groups and measured compliance by observing or weighing provided bars of soap as well as by tracking diarrhea cases. The studies report large positive effects of handwashing and soap provision programs on diarrhea incidence. Khan (1982) reports that the provision of either soap and water storage containers or soap alone, along with initial instructions to increase the frequency of handwashing, reduced shigella reinfection by 67 percent in Bangladesh. Han and Hlaing (1989) report a 40 percent reduction in diarrhea incidence among children under age two (though no reduction in incidence for older children) following handwashing education and the provision of soap to a random sample of mothers in Rangoon (Yangon).

\section{Point-of-Use Water Treatment}

Point-of-use water treatment and improved water storage practices reduce the microbacteriological contamination of water held in homes. Numerous technologies have been developed, including chemical disinfection, that rely on simple household bleach or other methods such as use of flocculants, adsorption, filtration, boiling, or solar disinfection.

Evidence from randomized evaluations assessing the health impacts of various interventions to improve water quality at the point of use suggests that this is a promising way to reduce diarrheal incidence (Semenza and others 1998; Quick, Venczal, and others 1999; Quick, Kimura, and others 2002; Sobsey, Handzel, and 
Venczel 2003; Reller and others 2003; Clasen and others 2004). Randomized impact evaluations of point-of-use water treatment systems observe statistically significant reductions of 20-30 percent in diarrheal incidence at the household level (Quick, Venczal, and others 1999; Reller and others 2003). ${ }^{3,4}$ In at least, one setting this level of reduction was sufficient to generate measurable reductions in mortality from all causes (Crump and others 2005).

\section{Strategies to Promote Individual Behavior Change}

The studies reviewed in this section suggest that the effectiveness of handwashing and point-of-use water treatment has been well established, and that attention should now be given to efforts to understand effective promotion strategies and how to sustain behavior change. The health benefits of this class of interventions depend on individual decisions to adopt and consistently adhere to certain behaviors. For both types of behavior, the observed impacts were generated in settings where high uptake (around 70 percent in the case of point-of-use water treatment) was supported by weekly or daily reminders by fieldworkers. Such extremely high-intensity contact with fieldworkers is prohibitively expensive to provide on a large-scale basis. ${ }^{5}$ The challenge of increasing uptake is further complicated by infectious disease externalities; because the private benefits of product use are smaller than the social benefits, to the extent that uptake affects the disease environment, inefficiently low levels of adoption can be expected even at subsidized product prices. Kremer and Miguel (forthcoming) describe such a phenomenon in the case of deworming drug use in western Kenya.

Identifying cost-effective ways to facilitate long-term behavior change and technology adoption requires additional research comparing alternative messages and message delivery avenues in several cultural contexts. ${ }^{6}$ For example, rigorous evaluations are needed that compare health education messages directed toward women emphasizing family health and those emphasizing children's well-being in particular. The comparative usefulness of positive and negative messages should also be explored, as has been done in other campaigns aimed at inducing behavioral changes in developed countries.

There is some evidence that inducing health or hygiene behavioral change may be especially difficult among the poorest groups. For example, Pant and others (1996) divided a random sample of 40,000 children from 75 locations in Nepal into two randomly assigned groups and provided one group with vitamin A supplements and the other with nutrition education. The risk of child mortality declined equally in the two groups, but the education program was more costly to deliver. In addition, education was the least cost-effective when maternal literacy was low. In the handwashing evaluation described above, Luby, Agboatwall, Painter, and others (2004) report that it took longer for the poorest households to 
increase their compliance with the program, resulting in lower initial reductions in diarrhea incidence compared with the full effect ultimately demonstrated.

In the case of point-of-use water treatment, another important next step is to examine whether people are willing to permanently adopt or pay for systems that affect the taste of water, slow the rate at which water can be consumed (filtration, for example), or require that traditional storage containers be abandoned (Makutsa and others 2001).

Donors and governments are likely to be especially interested in the impact of price on uptake in the market for point-of-use water treatment products. There is some new evidence on these questions in recent work by Ashraf, Berry, and Shapiro (2006). This randomized evaluation suggests that demand depends on the price for in-home chlorination products in Zambia, with 80 percent of a representative sample of households (in a door-to-door sale) agreeing to purchase a chlorine-based point-of-use water treatment product at a price that is about 60 percent less than the subsidized market price, and about 50 percent willing to purchase the product at the subsidized price available in markets. No information is available about the elasticity of demand at higher prices that would reflect full cost-recovery pricing.

Berry and Shapiro (2006) present evidence, based on random assignment of households, that charging a nonzero price screens out customers who are less likely to use the product. They argue that charging thus avoids waste of the product and so may be optimal even if the only goal is to maximize product use with a given budget. However, higher prices do not help target delivery of the product to families with small children, who benefit the most from cleaner water. Moreover, the observed non-use may reflect saving of the product for later use, perhaps during times of epidemics. Moreover, the waste is likely to be quantitatively much smaller in the context of an ongoing program, because while people may accept a few bottles and never use them, it is unlikely that they would accept bottles month after month that they would never use. It is much more likely that they would build up a small stock of the product, and then not take more free bottles unless they were depleting their existing stock. Thus, the waste potentially avoided by charging a positive price on the basis of screening considerations is likely to be small, unless people develop alternative uses for the product. Waste might be a greater concern for items with a one-time capital cost, like filtration devices, rather than for items with just a flow cost.

In fact, market-based distribution of sodium hypochlorite disinfectants introduces some inefficiency. Because sellers want small bottles with low retail prices and packaging is a large part of total production cost (nearly 67\% in Kenya, for example), the unit cost of producing these disinfectants (e.g., WaterGuard or Clorin) is higher than it would be if bulk packaging were used. If alternative distribution channels were used, there would be less need for small bottles and lower 
total costs to produce the same amount of disinfectant, because the solution itself is only about $7 \%$ of total production cost.

Ashraf, Berry, and Shapiro (2006) designed their study so that they also could test the claim that paying a positive price actually makes people more likely to use technologies like sodium hypochlorite disinfectants. If this were true, it could be a second argument for charging a price for such products. While there is some evidence of this phenomenon in their study, it is not statistically significant.

In some contexts and for some behaviors, households may not be the most cost-effective entry point for message dissemination. Evaluations are needed that examine the relative effectiveness and cost-effectiveness of community-level efforts to stimulate demand for services or hygiene education efforts like the Total Sanitation Campaign, a community-based campaign to encourage sanitary habits, with a special emphasis on eliminating open defecation near villages. Chaudhury and Hammer (2006) are currently evaluating the Total Sanitation Campaign in India, and an evaluation of the program in Bangladesh is also under way. Manandhar and others (2004) demonstrate that community-level education of women's groups can improve birth outcomes. Further work might assess whether such education efforts can influence other hygiene behaviors, and the scalability of this approach.

Other feasible delivery mechanisms for inducing sustained uptake might include programs that work through maternity clinics (potentially providing incentives for women to take up antenatal services) or school-based programs. It is possible, for example, that providing soap, handwashing facilities, and messages about the importance of handwashing after defecation in primary schools might be an effective and cost-effective means of promoting long-term behavior change.

Research is also needed to identify how social learning about hygiene behavior and water treatment occurs. For example, little is known about who the opinion leaders are for water-related matters, and identifying them and encouraging them to adopt treatment systems or hygiene behaviors might be critical to wider community adoption. Research could examine, for example, whether encouraging women's groups to use water treatment systems is a particularly effective means of targeting mothers of young children, and thus increasing uptake among the young when weaning occurs. Such targeted dissemination to women could be compared with targeted dissemination to political leaders (likely men) and wider service provision.

\section{Infrastructure Provision}

This section reviews the evidence on the provision of piped water and sanitation and of community-level infrastructure. 


\section{Piped Water and Sanitation}

There is strong evidence that large-scale investments in water and sanitation infrastructure can have massive impacts on child mortality. Cutler and Miller (2005) use historical variation in the timing and location of water filtration and chlorination technology adoption across U.S. cities to identify the contribution of improved water quality to the epidemiological transition in American cities. They find that clean water was responsible for about half the observed decline in mortality and nearly two-thirds of the reduction in child mortality in cities.

In a rural setting, Watson (2006) exploits the fact that a series of water and sanitation interventions introduced on Native American reservations in the United States during 1960-1998 were likely uncorrelated with other factors affecting infant health and plausibly exogenous to local community characteristics after accounting for county and year fixed effects. This research suggests that a 10 percent increase in the fraction of homes with improved water and sanitation services reduced infant mortality by 4 percent. Infant mortality rates fell among local residents not living on the reservation as well-a result Watson uses as a means to measure the significant positive externalities associated with the program.

An important question is how to deliver piped water and sanitation services in developing countries. There is some evidence that, at least in some settings, allowing private firms to provide piped water service can improve health outcomes. Galiani and others (2005) study a privatization reform that took place for about 30 percent of municipal water companies in Argentina in the 1990s to identify the impact of ownership on child health. They estimate that child mortality overall fell 5-7 percent in areas that privatized their water services because in this context privatization improved service and expanded coverage, and that the effect was largest in the poorest areas, at around 24 percent. While privatization of water supply is associated with significant reductions in deaths from infectious and parasitic diseases, it appears uncorrelated with deaths from causes unrelated to water conditions.

\section{Limited Rural Water and Sanitation Infrastructure}

A large body of epidemiological literature investigates the impact of improved rural water supply and sanitation service provision (often as part of a package of interventions that includes hygiene education) on health outcomes (reviews include Blum and Feachem 1983; Esrey, Feachem, and Hughes 1985; Esrey and Habicht 1986; Esrey and others 1991; Rosen and Vincent 1999; Fewtrell and others 2005).

Many of the studies that find health effects for water and sanitation infrastructure improvements short of piped water and sewerage suffer from critical methodological problems. Moreover, more recent research that addresses some of these 
problems seems to find little evidence of substantial health impacts from rural water infrastructure.

Some have interpreted the existing literature as suggesting that providing water infrastructure short of pipes is not enough on its own and must be combined with other interventions, such as improved sanitation or hygiene. As discussed in the following section however there does not seem to be much evidence for such complementarity and in fact there is some evidence against it. Even if complementarity exists between communal rural water infrastructure and other interventions at some level of provision, not enough is known about the nature of the complementarity to use this information operationally. Finally, there are not yet adequate models for maintaining small-scale rural infrastructure, as discussed later, although contracting methods deserve further exploration.

Two studies by Esrey and others (1991) and by Esrey (1996) argue that water infrastructure is less effective than sanitation provision and hygiene education in fighting diarrheal disease. These publications are frequently cited as evidence for the relative importance of sanitation investments and hygiene education over the provision of improved water (see, for example, USAID 1996; Vaz and Jha 2001; World Bank 2002). In a review of 25 studies deemed by the authors to be relatively rigorous, Esrey and others (1991) attempt to separate the impacts of water supply, sanitation, and hygiene education interventions on diarrheal illness. They conclude that either sanitation supply or hygiene education provision results in nearly twice the median reduction in diarrheal incidence as an investment in water quality alone or in water quantity and water quality together.

Using multivariate regression analysis of household infrastructure status and diarrhea prevalence from several countries, Esrey (1996) argues that the benefits of improved water quality occur only together with improved sanitation and only when there is a water source within the home. One hypothesis for the relative ineffectiveness of communal water infrastructure is that a high degree of recontamination of water occurs in transport and storage when people fail to wash their hands frequently. A low correlation between source and home water quality has been demonstrated frequently in nonexperimental data (Wright, Gundry, and Conroy 2004). A limited impact of communal water supply would also be consistent with an epidemiological model in which the primary causes of diarrheal disease are water-washed (not waterborne), in which case improvements in water quality are likely to be less effective than interventions that make handwashing less costly, such as providing taps.

Many studies of water and sanitation infrastructure provision in developing countries lack a plausible comparison group and thus, without a credible counterfactual, cannot isolate a causal treatment effect from service provision. In the case of sanitation, for example, several case-control studies that compare health outcomes among children presenting at hospitals or clinics with diarrhea and 
children with similar observable characteristics, but presenting with other illnesses (such as upper respiratory infections) have found that access to latrines reduces acute diarrhea incidence (Daniels and others 1990; Meddings and others 2004). However, this research strategy is vulnerable to the same methodological critique as cross-sectional regression analyses: cases that are similar across observable characteristics may differ systematically along dimensions that are difficult to measure, confounding the interpretation of results.

The two early evaluations (Huttly and others 1987; Aziz and others 1990) of infrastructure provision that used a prospective design, albeit in a very low number of communities, appeared to demonstrate that the provision of wells and latrines can be effective. Aziz and others (1990) compare the impact of an intervention in Bangladesh that provided multiple interventions, including water pumps, hygiene education, and latrines, to two villages ( 820 households) with three control villages (750 households), about $5 \mathrm{~km}$ away. The published article does not mention whether the villages were randomly selected. Children 6 months to 5 years of age in the intervention area experienced 25 percent fewer episodes of diarrhea than those in the comparison area.

Huttly and others (1987) and Blum and others (1990) study the impact of the provision of borehole wells with hand-pumps, pit latrines, and health education on dracunculiasis (guinea worm disease), diarrhea, and nutritional status in Nigeria in 1983-1986. The study compared three intervention villages (850 households) and two comparison villages (420 households). Because of implementation difficulties, their results largely reflect the effect of the installation of wells with pumps. The prevalence of wasting (defined as less than 80 percent of desirable weight for height) among children under 3 years of age declined significantly in the intervention villages, though diarrhea incidence did not decline measurably (perhaps because diarrhea is notoriously difficult to measure).

A key shortcoming of these studies is that they examine a very small number of communities, and the statistical hypothesis testing fails to adequately account for the fact that the interventions being evaluated are provided at the community rather than the household level. Because households within a community are likely to resemble each other, this clustered sampling reduces the power of statistical tests to determine the existence and size of the treatment effect, implying that reported confidence intervals are incorrect. To capture the variance in outcome variables across space and time, many localities should be included in both the treatment and comparison groups. Although the exact number of clusters required for a study depends on context-specific estimates of the intracluster correlation of outcome variables, Esrey (1996) suggests that at least 20 clusters should be included in both treatment and comparison samples.

More recent work in this area covers a large enough number of communities to draw statistical inferences, and finds little evidence that communal rural water 
infrastructure substantially improves health. Kremer and others (2006) evaluate a spring protection intervention at a sample of 1,200 households in 175 communities using a randomized approach as part of a larger impact evaluation of a series of water and hygiene interventions in western Kenya. They find that spring protection is very effective in improving the quality of water at the source. Among households that collected all of their drinking water from the sample spring at baseline, spring protection is also highly effective in improving household water quality. Nonetheless, preliminary results from a subset of the data suggest that the improvements in water quality do not have substantial effects on diarrhea incidence, child weight, or child height. Consistent with this, revealed preference estimates of willingness to pay for the improved-source water quality decline over time. There is also little evidence of significant spillover benefits of the program on neighboring communities. In related work, initial results from a World Bank financed five-armed randomized trial in Afghanistan indicate that only a combination of hygiene education, provision of wells, and treatment of water with dilute sodium hypochlorite had a significant effect on diarrhea incidence among all age groups (B. Loevinsohn 2007, Personal communication). No effect was found from these interventions, either alone or in combination, on diarrhea incidence among children under five.

\section{Complementarity between Source Water Quality and Other Factors}

Some researchers have argued that although improved communal water supply does not reduce diarrhea on its own, it does do so in combination with other interventions, and should therefore be part of a larger package.

Both Kremer and others (2006) and Luby and others (2006) use experimental approaches to directly address complementarity. Kremer and others (2006) estimate that access to sanitation or hygiene knowledge before an improved water supply program does not appear to enable households to better translate quality improvements in source water into either household water quality gains or health improvements in their study region in Kenya. Luby and others (2006) report the result of a clustered randomized control trial in Karachi in which a random sample of households received handwashing promotion and a random sample received point-of-use drinking water technologies. A subset of these households received both interventions. While each of the home-based interventions reduced diarrhea incidence, there was no statistically significant additional benefit from the combined intervention. That is, the interventions function more as substitutes than as complements.

As Luby and others (2006) discuss, their findings are consistent with an epidemiological model in which disease thresholds are qualitatively important. If a large proportion of diarrhea incidence is caused by pathogens that must be 
present in large doses to cause disease, substantially reducing the organisms ingested may reduce diarrhea incidence, but further marginal reductions could be much less important.

The results from these two studies suggest that it would be a mistake to assume that improvements in communal water supply will be effective in combination with other interventions. Even if complementarities are present in certain circumstances, without better knowledge of when they are important, this is of limited operational relevance.

\section{The Challenge of Infrastructure Maintenance}

To remain effective, water and sanitation infrastructure require management and upkeep. This section reviews the evidence on various infrastructure management schemes, cost-sharing efforts, and the involvement of women in managing public goods provision.

Infrastructure maintenance has historically been a major problem in developing countries, in particular in the rural water sector. For instance, a quarter of India's water infrastructure is believed to be in need of repair (Ray 2004). World Development Report 2004 (World Bank 2003) estimates that more than a third of rural water infrastructure in South Asia is not functional. Miguel and Gugerty (2005) report that in western Kenya nearly 50 percent of borehole wells dug in the 1980s, and subsequently maintained using a community-based maintenance model, had fallen into disrepair by 2000. Difficulties with maintaining water infrastructure, particularly in rural areas, reduce the cost-effectiveness of these interventions relative to other measures that prevent diarrhea.

Involving women in managing environmental public goods. Some of the sociology literature has predicted that increasing the involvement of women in user committees will improve the management of collectively owned natural resources because women's social networks provide them with prior experience with collective action (Agarwal 2000). In addition, since women are major users of these goods, women's involvement in creating the rules may be especially important for compliance (Zwarteveen and Meizen-Dick 2001).

However, the evidence on the impact of women's involvement in public goods management is limited. Efforts using laboratory experiments to assess whether women supply different levels of public goods than men or are more cooperative (Nowell and Tinkler 1994; Eckel and Grossman 1998; Solow and Kirkwood 2002) seem to be sensitive to the form of the experiment. Much of the field evidence on this question is hampered by concerns about reverse causality (for example, Dollar, Fisman, and Gatti 2001). It is difficult to determine whether the inclusion of women causes a particular outcome to occur, whether the fact that 
an outcome occurs encourages the participation and inclusion of women, or whether some other factors are driving these results. This problem affects both retrospective analyses (Prokopy 2004) and case studies (INSTRAW-UN 1990; Wijk-Sijbesma 1998; Gross, van Wijk, and Mukherjee 2001), neither of which is able to establish a causal relationship between women's participation and observed outcomes.

Chattopadhyay and Duflo (2004) identify a causal relationship between women's participation and project outcomes in their study of a randomized policy change in India that increased the role of women in policy decision-making. A 1993 constitutional amendment called for a third of village council leader positions to be reserved for women. Rules ensured random assignment of the leadership reservations. Chattopadhyay and Duflo (2004) show that village councils headed by women were more likely to invest in public infrastructure for drinking water, and, more generally, that councils dominated by one gender were more likely to invest in goods important to that gender. Of course, a finding that women are more likely to invest in water infrastructure does not necessarily imply that they will be more effective in maintaining it.

Community-level infrastructure management schemes. A standard model for maintaining donor-funded infrastructure projects in developing countries is to establish user groups responsible for maintenance and management. Giving communities direct control or ownership over key project decisions is intended to improve the quality of public services and increase financial sustainability, thus reducing the need for ongoing donor funding or involvement. ${ }^{7}$

There is little convincing empirical evidence, however, that local user-committee management of local public goods such as improved drinking water sources results in either greater financial sustainability or better quality service than ongoing centralized funding from public budgets. Collective action problems may be difficult to overcome, and voluntary committees tasked with collecting user fees may be difficult to sustain or empower. The rural water sector is characterized both by significant infectious disease externalities, as discussed earlier, and in most poor countries by weak fundraising capabilities because of weak local institutions generally.

In a recent comprehensive review of community-based development projects, Mansuri and Rao (2004) note that existing research examining "successful" community-based projects does not compare these projects with centralized mechanisms for service delivery or infrastructure maintenance (for example, city or state financed). This makes it difficult to determine whether alternative project designs would have had different results. The limited empirical evidence suggests the impact of the community-based development approach on infrastructure maintenance is mixed at best. ${ }^{8}$ 
Contracting for private maintenance service may be a promising alternative to committee-based management schemes. The evidence from Argentina discussed earlier (Galiani and others 2005) suggests that contracted private provision of service can expand coverage and improve health outcomes at least in certain settings or in middle-income countries. Several other nonrandomized studies in the water sector also provide suggestive evidence that continued support (financial and otherwise) may be necessary for effective infrastructure investments and public service delivery (Katz and Sara 1998; Dayton-Johnson 2000; Kleemeier 2000; Newman and others 2002). In other public health settings, contracting for private service provision has been demonstrated to be effective. Bloom and others (2006) show that government contracting of health services in Cambodia improved service at least for specifically targeted outcomes. Certainly, further research is needed that transparently compares the counterfactual of subsidized public service provision and community-based management schemes.

\section{Conclusion and Recommendations}

Randomized controlled trials have established that vaccination, oral rehydration therapy, breastfeeding, and micronutrient supplementation are effective in reducing the burden of diarrhea. Convincing evidence from rigorous evaluations has also demonstrated the effectiveness of point-of-use water treatment and handwashing. There is evidence that piped water and sanitation infrastructure can improve health and that private management of such services can work well. In contrast, there is little evidence of the effectiveness of communal rural water infrastructure in fighting diarrheal disease. Reviews of older work with retrospective data yield mixed results, but have generally found that sanitation and hygiene are more important than water quality. Two prospective studies indicated gains from communal water infrastructure in particular, but these are methodologically problematic. Recent randomized evaluations provide little evidence for substantial effects of communal water infrastructure on diarrheal disease. Communal water infrastructure may be effective in fighting diarrhea in certain environments, but unless this is demonstrated, other approaches seem a higher priority for reducing the burden of diarrheal disease.

While this review suggests that investments in communal water infrastructure may not be a priority for fighting diarrheal diseases, these projects may be justified on other grounds. Women's time may be freed from water transport duties. In urban and peri-urban areas, improved water supply may also free households of the need to purchase drinking water from vendors (Briscoe 1984; Okun 1988; Varley, Tarvid, and Chao 1998; Meddings and others 2004). Standard cost-benefit techniques can establish whether individual projects are justified on these grounds. 
More work is needed to develop and assess alternative strategies for generating sustained uptake of handwashing and point-of-use treatment of water. Where possible, projects should be designed from the outset to accommodate a rigorous evaluation. Projects should also be designed to allow for estimation of the impact of both individual interventions and packages of interventions, so that alternative approaches can be directly compared and issues of complementarity can be more fully assessed.

\section{Notes}

Alix Peterson Zwane (corresponding author) is Assistant Cooperative Extension Specialist in the Department of Agriculture and Resource Economics at the University of California, Berkeley and a member of the Giannini Foundation; her e-mail address is zwane@are.berkeley.edu. Michael Kremer is Gates Professor of Developing Societies in the Department of Economics at Harvard University and fellow at the National Bureau of Economic Research; his e-mail address is mkremer@fas.harvard. edu. This article builds on a report submitted to the Center for Global Development Global Health Policy Research Network. Support from the Brookings Institute, the Bill and Melinda Gates Foundation, Google.org, and the U.S. Department of Agriculture, Foreign Agricultural Service is gratefully acknowledged. Lucie Heinzerling, Anthony Keats, Jessica Leino, Kavita Shukla, Jesse Tack, and Heidi Williams provided valuable research assistance. The authors thank three anonymous reviewers, Jeff Albert, Tom Clasen, Rachel Glennerster, Ranjiv Khush, Daniele Lantagne, Steve Luby, Ted Miguel, Jesse Shapiro, and the participants in a Berkeley Water Center workshop on diarrheal diseases for helpful comments and discussion.

1. For other recent reviews, focusing primarily on medical effectiveness, see Keusch and others (2006), Cairncross and Valdmanis (2006), Fewtrell and others (2005), and Martines and others (1993).

2. Perhaps because of the endogenous relationship between diarrhea and malnutrition, some observational studies also suggest that early childhood diarrhea is correlated with reduced fitness and cognitive performance for children ages 6-9, but have not been able isolate a causal effect (Guerrant and others 1999; Berkman and others 2002; Niehaus and others 2002). Impact evaluations of programs providing food supplements to primary school children generally show a positive relationship with schooling and cognitive outcomes, in addition to nutritional indicators (Chavez and Martinez 1986; Martorell 1993; Pollitt and others 1993).

3. Despite these large reported gains, however, many of the same studies also find that the observed reductions in diarrhea incidence associated with the intervention are concentrated among children under age one and over age five. Surprisingly, the age group with the highest rate of diarrhea incidence, children ages 1-5, may be least affected by this intervention (Quick, Venczal, and others 1999; Reller and others 2003; Sobsey and others 2003). However, in two cases, larger gains from point-of-use water treatment are identified in children under age five. In Uzbekistan, diarrhea incidence in children under five fell by 85 percent after the provision of a chlorine-stock solution and a narrow-necked storage container. In rural Bolivia, Clasen and others (2004) identified reductions in diarrhea incidence of about 83 percent in children under age five with a sample size of 30 children in 50 households. In this case, the treatment system provided to households was a ceramic water filter that left the taste of water unchanged. Uptake appears to have been around 70 percent, suggesting that improved compliance with treatment relative to the studies that supplied disinfectant cannot explain the observed result. It is unclear why the large gains identified in these two studies for the most vulnerable group have not been found in other contexts. 
4. Findings from a few randomized trial studies of solar disinfection of water in homes are also consistent with this conclusion. In a Maasai community in Kenya, researchers identified large health benefits for children under six from the exposure of drinking water to sunlight (Conroy and others 1999, 2001).

5. Some follow-up studies several years after soap provision and hygiene behavior change efforts find that the behavior change can persist (Wilson and Chandler 1993; Shordt and Cairncross 2004). However, as the initial interventions studied were not randomized, this finding is somewhat difficult to interpret. A follow-up study, 5 years after a quasi-randomized community-level education intervention in Bangladesh (described in greater detail later in this article), suggests that the hygiene education effort there may have been relatively ineffective as 5 years later treatment households did not exhibit better hygiene than control households (Hoque and others 1996).

6. Low handwashing rates in U.S. elementary schools have prompted interest in the use of instant hand sanitizers (which do not require water) in classrooms as an alternative means of breaking disease transmission. A review of the evidence on the efficacy of sanitizers (Meadows and Le Saux 2004) identified one (clustered) randomized control trial of this technology to date. That trial found that sanitizers can effectively reduce absenteeism as a result of illness (White and others 2001). Based solely on that study, it is unclear whether sanitizers may be suitable for a developing country context, but this may be another avenue for future research.

7. Other goals may also be important. For example, community-based development may be expected to empower poor people or strengthen local governance.

8. In a study of water projects in 44 Indonesian villages, Isham and Kahkonen (1999) find that the existence of local water committees had either no effect or a negative effect on service performance, though greater community participation in the design of community-based water projects did improve water supply and health outcomes somewhat. On the other hand, Khwaja (2003) finds that community-managed projects in Pakistan, including investments in irrigation and drinking water, performed better than projects implemented by the government without community participation. However, he also finds that project-specific factors, such as the quality of the outside facilitator, may have a larger impact on project success than community characteristics.

\section{References}

Agarwal, B. 2000. "Conceptualizing Environmental Collective Action: Why Gender Matters.” Cambridge Journal of Economics 24(3):283-310.

Ashraf, N., J. Berry, and J. M. Shapiro. 2006. Can Higher Prices Stimulate Product Use? Evidence from a Field Experiment in Zambia. Cambridge, Mass: Harvard Business School.

Aziz, K., B. Hoque, K. Hasan, M. Patwary, S. Huttly, M. Rahaman, and R. Feachem. 1990. "Reduction in Diarrhoeal Diseases in Children in Rural Bangladesh by Environmental and Behavioral Modifications." Transactions of the Royal Society of Tropical Medicine and Hygiene 84(3):433-38.

Beaton, G. H., R. Martorell, K. A. L'Abbé, B. Edmonston, G. McCabe, A. C. Ross, and B. Harvey. 1993. "Effectiveness of Vitamin A Supplementation in the Control of Young Child Mortality in Developing Countries." Nutrition Policy Discussion Paper 13. United Nations Administrative Committee on Coordination, Subcommittee on Nutrition, Geneva.

Berkman, D. S., A. G. Lescano, R. H. Gilman, S. L. Lopez, and M. M. Black. 2002. "Effects of Stunting, Diarrhoeal Disease, and Parasitic Infection During Infancy on Cognition in Late Childhood: A Follow-Up Study." Lancet 359(9306):564-71.

Bloom, Erik, Elizabeth King, Michael Kremer, Indu Bhushan, David Clingingsmith, Benjamin Loevinsohn, Rathavuth Hong, and J. Brad Schwartz. 2006. Contracting for Health: Evidence from Cambodia. Cambridge, Mass: Harvard University. 
Black, R. E. 1998. “Therapeutic and Preventive Effects of Zinc on Serious Childhood Infections Diseases in Developing Countries.” American Journal of Clinical Nutrition 68(supplement):p476s-79s.

Blum, D., and R. G. Feacham. 1983. "Measuring the Impact of Water Supply and Sanitation Investments on Diarrheal Diseases: Problems of Methodology.” International Journal of Epidemiology 12(3):357-65.

Blum, D., R. Emeh, S. R. A. Huttly, O. Dosunmu-Oganbe, N. Okeke, M. Ajala, J. I. Okora, C. Akeijobi, B. R. KirkwoodR. G. Feachem. 1990. "The Imo State (Nigeria) Drinking Water Supply and Sanitation Project 2: Impact on Dracunculiasis, Diarrhoea, and Nutritional Status." Transactions of the Royal Society of Tropical Medicine and Hygiene 84(2):316-21.

Briend, A. 1990. "Is Diarrhea a Major Cause of Malnutrition among the Under-Fives in Developing Countries? A Review of Available Evidence." European Journal of Clinical Nutrition 44:611-28.

Briscoe, J. 1984. "Water Supply and Health in Developing Countries: Selective Primary Health Care Revisited." American Journal of Public Health 74(9):1009-13.

Cairncross, S. 1996. "Water Quality, Quantity, and Health.” In J. O. Drangert, R. Swiderski, and M. Woodhouse eds., Safe Water Environments. Water and Environmental Health Studies 24. Sweden: Linkoping University.

Cairncross, S., and V. Valdmanis. 2006. "Water Supply, Sanitation, and Hygiene Promotion.” In Jamison others eds., Disease Control Priorities in Developing Countries, 2nd ed. New York: Oxford University Press.

Chattopadhyay, R., and E. Duflo. 2004. "Women as Policy Makers: Evidence from a Randomized Policy Experiment in India.” Econometrica 72(5):1409-43.

Chaudhury, N., and J. Hammer. 2006. Sanitation and Child Health: Evaluation of a Randomized Hygiene and Sanitation Information Campaign in an Indian State. World Bank, Development Economics Research Group, Washington, D.C.

Chavez, A.V., and C. Martinez. 1986. "Efectos de la Desnutricion Moderada Sobre el Rendimiento Escolar Temprano." La Revista de Investigacion Clinica 38(Suplemento):115-19.

CHR (Child Health Research Project). 1998. "Childhood Diarrhea in Sub-Saharan Africa.” Child Health Research Project Special Report, 2(1). Cambridge, Mass.

Clasen, T. F., G. Parra, S. Boisson, and S. Collin. 2004. "Reducing Diarrhea Through the Use of Household-Based Ceramic Water Filters: A Randomized Controlled Trial in Rural Bolivia.” American Journal of Tropical Medicine and Hygiene 70(6):651-57.

Conroy, R. M., M. Meegan, T. Joyce, K. McGuigan, and J. Barnes. 1999. "Solar Disinfection of Water Reduces Diarrheal Disease: An Update." Archives of Disease in Childhood 81(4):337-8.

2001. "Solar Disinfection of Drinking Water Protects Against Cholera in Children Under Six Years of Age." Archives of Disease in Childhood 85(4):293-95.

Crump, J. A., P. O. Otieno, L. Slutsker, B. Keswick, D. Rosen, R. Hoekstra, J. Vulule, and S. Luby. 2005. "Household Based Treatment of Drinking Water with Flocculant-Disinfectant for Preventing Diarrhoea in Areas with Turbid Source Water in Rural Western Kenya: Cluster Randomised Controlled Trial.” British Medical Journal 331:478-83.

Curtis, V., and S. Cairncross. 2003. "Effect of Washing Hands with Soap on Diarrhea Risk: A Systematic Review." Lancet Infectious Disease 3(5):275-81.

Curtis, V., S. Cairncross, and R. Yonli. 2000. "Domestic Hygiene and Diarrhea-Pinpointing the Problem." Tropical Medicine and International Health 5(1):22-32.

Cutler, D., and G. Miller. 2005. "The Role of Public Health Improvements in Health Advances: The 20th Century United States.” Demography 42(1):1-22.

Daniels, D. L., S. Cousens, L. Makoae, and R. Feachem. 1990. "A Case-Control Study of the Impact of Improved Sanitation on Diarrhea Morbidity in Lesotho.” Bulletin of the World Health Organization 68(4):455-64.

Dayton-Johnson, J. 2000. "The Determinants of Collective Action on the Commons: A Model with Evidence from Mexico." Journal of Development Economics 62:181-208. 
Dollar, D., R. Fisman, and R. Gatti. 2001. "Are Women Really the 'Fairer' Sex? Corruption and Women in Government." Journal of Economic Behavior and Organization 46(4):423-29.

Eckel, C., and P. J. Grossman. 1998. "Are Women Less Selfish Than Men? Evidence from Dictator Experiments." Economic Journal 198:726-35.

A, Esrey S. 1996. "Waste, Water, and Well-Being: A Multicountry Study." American Journal of Epidemiology 143(6):608-22.

Esrey, S. A., and J.-P. Habicht. 1986. "Epidemiologic Evidence for Health Benefits from Improved Water and Sanitation in Developing Countries.” Epidemiology Review 8:117-28.

Esrey, S. A., R. Feachem, and J. Hughes. 1985. "Interventions for the Control of Diarrheal Diseases among Young Children: Improving Water Supplies and Excreta Disposal Facilities." Bulletin of the World Health Organization 63(4):757-72.

Esrey, S. A., J. B. Potash, L. Roberts, and C. Shiff. 1991. "Effects of Improved Water Supply and Sanitation on Ascariasis, Diarrhea, Dracunculiasis, Hookworm Infection, Schistosomiasis, and Trachoma." Bulletin of the World Health Organization 69(5):609-21.

Fewtrell, L., R. B. Kaufmann, D. Kay, W. Enanoria, L. Haller, and J. M. Colford. 2005. "Water, Sanitation, and Hygiene Interventions to Reduce Diarrhoea in Less Developed Countries: A Systematic Review and MetaAnalysis." Lancet Infectious Diseases 5(1):42-52.

Galiani, S., P. Gertler, and E. Schargrodsky. 2005. "Water for Life: The Impact of the Privatization of Water Services on Child Mortality." Journal of Political Economy 113(1):83-120.

Gross, B., C. van Wijk, and N. Mukherjee. 2001. "Linking Sustainability with Demand, Gender, and Poverty: A Study in Community-Managed Water Supply Projects in 15 Countries.” World Bank Water and Sanitation Program, Washington, D.C.

Grotto, I., M. Mimouni, M. Gdalevich, and D. Mimouni. 2003. "Vitamin A Supplementation and Childhood Morbidity from Diarrhea and Respiratory Infections: A Meta-Analysis.” Journal of Pediatrics 142: $297-304$.

Guerrant, D. I., S. Moore, A. Lima, P. Patrick, J. Schorling, and R. Guerrant. 1999. "Association of Early Childhood Diarrhea and Cryptosporidiosis with Impaired Physical Fitness and Cognitive Function Four to Seven Years Later in a Poor Urban Community in Northeast Brazil.” American Journal of Tropical Medicine and Hygiene 61(5):707-13.

Guerrant, R. L., A. M. Aldo Lima, and Frances Davidson. 1992. "Diarrhea as a Cause and Effect of Malnutrition: Diarrhea Prevents Catch-up Growth and Malnutrition Increases Diarrhea Frequency and Duration." American Journal of Tropical Medicine and Hygiene 47(1):28-35.

Han, A. M., and T. Hlaing. 1989. "Prevention of Diarrhoea and Dysentery by Hand Washing." Transactions of the Royal Society of Tropical Medicine and Hygiene 83(1):2128-31.

Hendricks, K. M., and S. H. Badruddin. 1994. "Weaning and Diarrheal Disease." Journal of Diarrhoeal Disease Research 12(1):4-13.

Hill, Z., B. Kirkwood, and K. Edmond. 2004. "Family and Community Practices that Promote Child Survival, Growth, and Development: A Review of the Evidence." World Health Organization, Geneva.

Hoque, B. A., T. Juncker, R. Sack, M. Ali, and K. Aziz. 1996. "Sustainability of a Water, Sanitation and Hygiene Education Project in Rural Bangladesh: A 5-Year Follow-Up." Bulletin of the World Health Organization 74(4): $431-37$.

Huttly, S. R., A. D. Blum, B. R. Kirkwood, R. N. Emeh, and R. G. Feachem. 1987. "The Epidemiology of Acute Diarrhea in a Rural Community in Imo State, Nigeria." Transactions of the Royal Society of Tropical Medicine and Hygiene 81:865-70.

IIED (International Institute for Environment and Development). 2000. "Drawers of Water II: Thirty Years of Change in Domestic Water Use and Environmental Health in East Africa." International Institute for Environment and Development, London. 
INSTRAW-UN (International Research and Training Institute for the Advancement of Women). 1990. "Women, Water and Sanitation.” In S. Sontheimer ed., Women and the Environment: A Reader. New York, N.Y.: Monthly Review Press.

Isham, J., and S. Kahkonen. 1999. "What Determines the Effectiveness of Community-Based Water Projects? Evidence from Central Java, Indonesia on Demand Responsiveness, Service Rules, and Social Capital.” Social Capital Initiative Paper 14. World Bank, Environmentally and Socially Sustainable Development Network, Washington, D.C.

Iyer, Param, Jennifer Davis, Elif Yavuz, and Barbara Evans. 2006. "Rural Water Supply, Sanitation, and Hygiene: A Review of 25 Years of World Bank Lending (1978-2003)." World Bank Water Supply and Sanitation Working Note 10. World Bank Water and Sanitation Program, Washington, D.C.

Katz, T., and J. Sara. 1998. "Making Rural Water Supply Sustainable: Recommendations from a Global Study." United Nations Development Programme and World Bank Water and Sanitation Program, Washington, D.C. (www.wsp.org/publications/global_ruralstudy.pdf).

Keusch, G. T., O. Fontaine, A. Bhargava, C. Boschi-Pinto, Z. Bhutta, E. Gotuzzo, J. Rivera, J. Chow, S. ShahidSalles R. Laxminarayan. 2006. "Diarrheal Diseases." In Jamison others eds., Disease Control Priorities in Developing Countries, 2nd edn. New York: Oxford University Press.

Khan, M. U. 1982. "Interruption of Shigellosis by Hand Washing." Transactions of the Royal Society of Tropical Medicine and Hygiene 76(2):164-68.

Khwaja, A. I. 2003. Can Good Projects Succeed in Bad Communities? The Determinants of Collective Success in Maintaining Local Public Goods. Working Paper RWP01-043. Cambridge, Mass: Harvard University, Kennedy School of Government.

Kleemeier, E. 2000. "The Impact of Participation on Sustainability: an Analysis of the Malawi Rural Piped Scheme Program.” World Development 28(5):929-44.

Kosek, M., C. Bern, and R. L. Guerant. 2003. "The Global Burden of Diarrheal Disease, As Estimated from Studies Published between 1992 and 2000." Bulletin of the World Health Organization 81(3):197-204.

Kremer, M., J. Leino, E. Miguel, and A. Zwane. 2006. Spring Cleaning: Results from a Randomized Impact Evaluation of a Source Water Quality Improvement. Berkeley: University of California.

Kremer, M., and E. Miguel Forthcoming. "The Illusion of Sustainability.” Quarterly Journal of Economics.

Lanata, C. F. 2003. "Studies of food hygiene and diarrhoeal disease." International Journal of Environmental Health Research 13(Suppl 1):S175-83.

Lancet. 1991. "Diarrhea and Malnutrition.” Lancet 338:921-22.

Luby, S., M. Agboatwalla, A. Razz, and J. Sobel. 2004. "A Low-Cost Intervention for Cleaner Drinking Water in Karachi, Pakistan.” International Journal of Infectious Diseases 5(3):144-50.

Luby, S., M. Agboatwalla, J. Painter, A. Altaf, W. Billhimer, and R. Hoekstra. 2004. "Effect of Intensive Hand Washing Promotion on Childhood Diarrhea in High-Risk Communities in Pakistan: A Randomized Control Trial." Journal of the American Medical Association 291(21):2547-54.

Luby, S., M. Agboatwalla, J. Painter, A. Altaf, W. Billhimer, B. Keswick, and R. Hoekstra. 2006. "Combining Drinking Water Treatment and Hand Washing for Diarrhea Prevention: A Cluster Randomized Control Trial.” Tropical Medicine and International Health 11(4):479-89.

Manandhar, D., D. Osrin, B. Prasad, N. Mesko, K. Tumbahangphe, S. Tamang, S. Thapa, and others. 2004. "Effect of a Participatory Intervention with Women's Groups on Birth Outcomes in Nepal: Cluster Randomized Control Trial.” Lancet 364:970-79.

Makutsa, Philip, Kilungu Nzaku, Paul Ogutu, Peter Barasa, Sam Ombeki, Alex Mwaki, and Robert E. Quick, (2001), "Challenges in Implementing a Point-of-Use Water Quality Intervention in Rural Kenya." American Journal of Public Health 91(10):1571-73.

Mansuri, G., and V. Rao. 2004. “Community-Based and -Driven Development: A Critical Review.” World Bank Research Observer 19(1):1-39. 
Martines, J., M. Phillips, and R. G. Feachem. 1993. "Diarrheal Diseases.” In Dean T. Jamison, W. Henry Mosley, and Anthony R. Meachem eds., Disease Control Priorities in Developing Countries. New York: Oxford University Press.

Martorell, R. 1993. "Enhancing Human Potential in Guatemalan Adults through Improved Nutrition in Early Childhood.” Nutrition Today (January/February):6-13.

Meadows, E., and N. Le Saux. 2004. "A Systematic Review of the Effectiveness of Antimicrobial Rinse-Free Hand Sanitizers for Prevention of Illness-Related Absenteeism in Elementary School Children.” BMC Public Health $4: 50-51$.

Meddings, D. R., L. Ronald, S. Marion, J. Pinera, and A. Oppliger. 2004. "Cost Effectiveness of a Latrine Revision Programme in Kabul, Afganistan.” Bulletin of the World Health Organization 82(4):281-89.

Miguel, E., and M. K. Gugerty. 2005. “Ethnic Divisions, Social Sanctions, and Public Goods in Kenya.” Journal of Public Economics 89(11-12):2325-68.

Miller, P., and N. Hirschhorn. 1995. "The Effect of a National Control of Diarrheal Diseases Program on Mortality: The Case of Egypt.” Social Science Medicine 40(10):1-30.

Monte, C. M., A. Ashworth, M. K. Nations, A. A. Lima, A. Barreto, and S. R. Huttly. 1997. "Designing Educational Messages to Improve Weaning Food Hygiene Practices of Families Living in Poverty." Social Science Medicine 44(10):1453-64.

Motarjemi, Y., F. Kaferstei, G. Moy, and F. Quevedo. 1993. “Contaminated Weaning Food: A Major Risk Factor for Diarrhoea and Associated Malnutrition.” Bulletin of the World Health Organization 71(1):79-92.

Newman, J., M. Pradhan, L. Rawlings, G. Ridder, R. Coa, and J. Evia. 2002. "An Impact Evaluation of Education, Health, and Water Supply Investments by the Bolivian Social Investment Fund." World Bank Economic Review 16(2):241-74.

Niehaus, M. D., S. Moore, P. Patrick, L. Derr, B. Lorntz, and A. Lima. 2002. "Early Childhood Diarrhea is Associated with Diminished Cognitive Function Four to Seven Years Later in Children in a Northeast Brazilian Shantytown." American Journal of Tropical Medicine and Hygiene 66(5):590-93.

Nowell, C., and S. Tinkler. 1994. "The Influence of Gender on the Provision of a Public Good." Journal of Economic Behavior and Organization 25(1):25-36.

Okun, D. A. 1988. "The Value of Water Supply and Sanitation in Development: An Assessment." American Journal of Public Health 78(11):1463-67.

Pant, C. R., G. Pokharel, F. Curtale, R. Pokharel, R. Grosse, J. Lepkowski, Muhilal, M. Bannister, J. Gorstein, S. Pak-Gorstein, and others. 1996. "Impact of Nutrition Education and Mega-Dose Vitamin A Supplementation on the Health of Children in Nepal." Bulletin of the World Health Organization 74(5):533-45.

Parashar, U. D., J. S. Bresee, and R. I. Glass. 2003. "The Global Burden of Diarrhoeal Disease in Children." Bulletin of the World Health Organization 81(4):236 (Epub 2003 May 16).

Pelltier, D. E. Frongillo, D. Schroeder, and J. Habicht. 1995. "The Effects of Malnutrition on Child Mortality in Developing Countries." Bulletin of the World Health Organization 73(4):443-48.

Perera, B. J. C., S. Ganesan, J. Jayarasa, and S. Ranaweera. 1999. "The Impact of Breastfeeding Practices on Respiratory and Diarrhoeal Disease in Infancy: A Study from Sri Lanka.” Journal of Tropical Pediatrics 45(2): $115-18$.

Pollitt, E., K. S. Gorman, P. S. Engle, R. Martorell, and J. Rivera. 1993. "Early Supplementary Feeding and Cognition.” Monographs of the Society for Research in Child Development 58(7):1-99.

Prokopy, L. S. 2004. “Women's Participation in Rural Water Supply Projects in India: Is it Moving Beyond Tokenism and Does it Matter?” Water Policy 6(2):103-16.

Quick, R. E., L. Venczal, E. Mintz, L. Soleto, J. Aparicio, M. Gironaz, L. Hutwagner, and others. 1999. "Diarrhea Prevention in Bolivia through Point-of-Use Disinfection and Safe Storage: A Promising New Strategy." Epidemiology Infections 122(1):83-90. 
Quick, R. E., A. Kimura, A. Thevos, M. Tembo, I. Shamputa, L. Hutwagner, and E. Mintz. 2002. "Diarrhea Prevention through Household-Level Water Disinfection and Safe Storage in Zambia." American Journal of Tropical Medicine and Hygiene 66(5):584-89.

Ramakrishnan, U., and R. Martorell. 1998. "The Role of Vitamin A in Reducing Child Mortality and Morbidity and Improving Growth." Salud Publica de Mexico 40(2):189-98.

Ray, I. 2004. "Water for All? Peri-Urban and Rural Water Delivery Options: The Case of India." Paper Presented to the University of California, Berkeley, Energy and Resources Group Fall Colloquium Series, 6 October.

Raisler, J., C. Alexander, and P. O'Compo. 1999. "Breastfeeding and Infant Illness: A Dose-Response Relationship?" American Journal of Public Health 89(1):25-30.

Reller, E., C. Mendoza, M. Lopez, M. Alvarez, R. Hoekstra, C. Olson, K. Baier, B. Keswick, and S. Luby. 2003. "A Randomized Control Trial of Household-Based Flocculant-Disinfectant Drinking Water Treatment for Diarrhea Prevention in Rural Guatemala.” American Journal of Tropical Medicine and Hygiene 69(4):411-19.

Rosen, S., and J. R. Vincent. 1999. "Household Water Resources and Rural Productivity in Sub-Saharan Africa: A Review of the Evidence." Harvard Institute for International Development Discussion Paper 673. Cambridge, Mass.

Ruiz-Palacios, G., I. Pérez-Schael, F. Velázquez, H. Abate, T. Breuer, S. Costa Clemens, B. Cheuvart, and others. 2006. "Safety and Efficacy of an Attenuated Vaccine against Severe Rotavirus Gastroenteritis." New England Journal of Medicine 354(1):11-22.

Schorling, J .B., J. F. McAuliffe, M. A. de Souza, and R. L. Guerrant. 1990. "Malnutrition is Associated with Increased Diarrhea Incidence and Duration among Children in an Urban Brazilian Slum.” International Journal of Epidemiology 19(3):728-35.

Semenza, J., L. Roberts, A. Henderson, J. Bogan, and C. Rubin. 1998. "Water Distribution System and Diarrheal Disease Transmission: A Case Study in Uzbekistan." American Journal of Tropical Medicine and Hygiene 59(6): $941-46$.

Shordt, K., and S. Cairncross. 2004. Sustainability of Hygiene Behaviour and the Effectiveness of Change Interventions: Findings from a Multi-Country Research and Implications for Water and Sanitation Programmes. The Hague: International Water and Sanitation Centre.

Sikorski, J., M. J. Renfrew, S. Pindoria, and A. Wade. 2003. "Support for Breastfeeding Mothers: A Systematic Review." Paediatric and Perinatal Epidemiology 17(4):407-17.

Smith, K. R., C. F. Corvalan, and T. Kjellstrom. 1999. "How Much Global Ill Health Is Attributable to Environmental Factors?" Epidemiology 10(5):573-84.

Sobsey, M. D., T. Handzel, and L. Venczel. 2003. "Chlorination and Safe Storage of Household Drinking Water in Developing Countries to Reduce Waterborne Disease.” Water Science and Technology 47(3):221-28.

Solow, J., and N. Kirkwood. 2002. "Group Identity and Gender in Public Goods Experiments.” Journal of Economic Behavior and Organization 48(4):403-12.

USAID (United States Agency for International Development). 1996. Environment, Health and People: An Update on USAID's Environmental Health Project. USAID Environmental Health Project. Arlington, VA.

—. 2004. "Cost Analysis of the National Vitamin A Supplementation Programs in Ghana, Nepal, and Zambia: A Synthesis of Three Studies.” USAID Micronutrient Program, Arlington, VA.

Varley, R. C. G., J. Tarvid, and D. Chao. 1998. "A Reassessment of the Cost-Effectiveness of Water and Sanitation Interventions in Programmes for Controlling Childhood Diarrhea." Bulletin of the World Health Organization 76(6):617-31.

Vaz, L., and P. Jha. 2001. "Note on the Health Impact of Water and Sanitation Services." World Health Organization Commission on Macroeconomics and Health Working Paper Series Paper WG5: 23, Geneva.

Vesikari, T., D. Matson, P. Dennehy, P. Van Damme, M. Santosham, Z. Rodriguez, M. Dallas, and others. 2006. "Safety and Efficacy of a Pentavalent Human-Bovine (WC3) Reassortant Rotavirus Vaccine." New England Journal of Medicine 354:23-33. 
Victora, C. G., M. Olino, L. Nobre, and F. Barros. 1996. "Falling Diarrhoea Rates in Northeastern Brazil: Did ORT Play a Role?” Health Policy and Planning 11(2):132-41.

Victora, C. G., J. Bryce, O. Fontaine, and R. Monasch (2000). "Reducing Deaths from Diarrhea through Oral Rehydration Therapy.” Bulletin of the World Health Organization 78(10):1246-56.

Watson, T. 2006. "Public Health Investments and the Infant Mortality Gap: Evidence from Federal Sanitation Interventions and Hospitals on U.S. Indian Reservations.” Journal of Public Economics 90(8-9):1537-60.

White, C. G., F. Shinder, L. Shinder, and D. Dyer. 2001. "Reduction of Illness Absenteeism in Elementary Schools Using an Alcohol-Free Instant Hand Sanitizer.” Journal of School Nursing 17(5):258-65.

White, G. F. D. Bradley, and A. White. 1972. Drawers of Water: Domestic Water Use in East Africa. Chicago: University of Chicago Press.

WHO (World Health Organization). 2000. Global Water Supply and Sanitation Assessment. Geneva: WHO. 2002. World health report 2002. Geneva: WHO.

WHO Collaborative Study Team on the Role of Breastfeeding on the Prevention of Infant Mortality. 2000. "Effect of Breastfeeding on Infant and Child Mortality Due to Infectious Diseases in Less Developed Countries: A Pooled Analysis.” Lancet 355(9202):451-55.

van Wijk-Sijbesma, C. 1998. Gender in Water Resources Management, Water Supply, and Sanitation: Roles and Realities Revisited. The Hague: International Water and Sanitation Centre.

Wilson, J., and G. Chandler. 1993. "Sustained Improvements in Hygiene Behaviour Amongst Village Women in Lombok, Indonesia." Transactions of the Royal Society of Tropical Medicine and Hygiene 87(6):615-16.

World Bank. 2002. Water, Sanitation, and Hygiene at a Glance. World Bank: Washington, D.C.

- 2003. World Development Report 2004: Making Services Work for Poor People. Washington, D.C., World Bank.

Wright, J. S. Gundry, and R. Conroy. 2004. "Household Drinking Water in Developing Countries: A Systematic Review of Microbiological Contamination between Source and Point of Use." Tropical Medicine and International Health 9(1):106-17.

Zinc Investigators' Collaborative Group. 1999. "Prevention of Diarrhea and Pneumonia by Zinc Supplementation in Children in Developing Countries: Pooled Analysis of Randomized Control Trials." Journal of Pediatrics 135(6):689-97.

- 2000. "Therapeutic Effects of Oral Zinc in Acute and Persistent Diarrhea in Children in Developing Countries: Pooled Analysis of Randomized Control Trials.” American Journal of Clinical Nutrition 72:1516-22.

Zlotkin, S. H., C. Schauer, A. Christofides, W. Sharieff, M. Tondeur, and S. Hyder. 2005. "Micronutrient Sprinkles to Control Childhood Anemia." PLoS Medicine 2(1):24-28.

Zwarteveen, M., and R. Meizen-Dick. 2001. "Gender and Property-Rights in the Commons: Examples of Water Rights in South Asia." Agriculture and Human Values 18(1):11-25. 